\title{
GESTÃO PRISIONAL DO MONITORAMENTO ELETRÔNICO DE APENADOS DA 5 REGIÃO DO ESTADO DO RIO GRANDE DO SUL
}

\author{
Cleidson Teixeira Vinhas ${ }^{1}$ \\ Rodrigo Corrêa Sosa ${ }^{2}$ \\ Clóvis Dilli ${ }^{3}$ \\ Gustavo Leite da Silva ${ }^{4}$ \\ Alef Saizer Fiori ${ }^{5}$ \\ Marcio Orelio Santos da Silva ${ }^{6}$
}

RESUMO: O presente artigo tem como objetivo apresentar as inovações técnicas no que tange o setor de monitoramento eletrônico dos apenados da $5^{\underline{a}}$ Região do RS, que cumprem pena de detenção nos regimes semiaberto, fechado, aberto, ou, medidas alternativas. Com o intuito da utilização da modernidade e o emprego do uso de tornozeleiras eletrônicas, tendo como consequência o aprimoramento do sistema prisional do Estado do Rio Grande do Sul, possibilitando dessa forma a reinserção do custodiado a sociedade e o retorno ao seu âmbito familiar. A tecnologia faz parte da sociedade e está à disposição de todos que procuram se beneficiar e em diferentes segmentos da sociedade, inclusive nos órgãos públicos, não seria diferente a contribuição dos equipamentos digitais no sistema prisional. A alternativa apresentada neste trabalho visa proporcionar aos usuários e profissionais penitenciários uma estrutura com ideias necessárias para que os erros que possam ser cometidos possam ser atenuados gradativamente no setor da segurança pública.

Palavras-chave: Capacitação. Tecnologia digital. Modernização. Estruturação.

\section{INTRODUÇÃO}

O projeto faz menção à gestão prisional do monitoramento eletrônico da $5^{\text {a }}$ Região-RS (sigla IPME5). Este estabelecimento penal tem com finalidade a instalação de tornozeleiras eletrônicas nos apenados que cumprem penas em regime semiaberto, fechado, aberto e medidas alternativas, na região já mencionadaneste projeto.

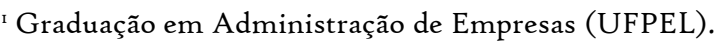

${ }^{2}$ Graduação em Tecnologias de processos Gerenciais pelo Centro Universitário Uninter.

3 Pós- Graduação em Gestão de Sistemas Prisionais pela Faculdade Instituto Brasil de Ensino - IBRA (FAMEV). PósGraduação em Segurança Pública pela Faculdade Instituto Brasil de Ensino- IBRA (FAMEV). Graduação em Tecnologias de processos Gerenciais pelo Centro Universitário Uninter.

${ }^{4}$ Graduação e mestrado em Meteorologia pela Universidade Federal de Pelotas - UFPel, Licenciatura em Ciências Sociais com Ênfase em Sociologia.

5 Pós- graduado em Gestão de Sistema Prisional. Faculdade Ibra. Licenciatura em Educação Física (anhanguera)

${ }^{6}$ Pós- graduação Lato Sensu em Direito Penal e Processual Penal (Faveni). Graduação em Licenciatura em História (Faveni). Graduação em Tecnologia dos Recursos Humanos (Anhanguera) Graduação em tecnologia em Gestão Pública (Anhguera). Pós- graduação lato sensu em Gestão Prisional (Faveni). Pósgraduação Lato Sensu em Segurança Pública (São Braz)
} 
A implementação do uso de tornozeleiras eletrônicas no sistema penal Brasileiro, foi inicialmente realizada nos estados: Rio Grande do Sul, Rio de Janeiro, São Paulo e Paraíba, com a finalidade de desafogar as prisões, devido a superlotação das cadeias brasileiras. Para os especialistas do assunto e para o poder Judiciário, tal inovação, seria uma solução para a problemática dasuperlotação do sistema carcerário brasileiro, já podemos verificar que até este momento, é percebido o êxito no investimento do estado do RS nesta área. Porém para a obtenção de melhores resultados, há necessidade de maior investimento na qualificação técnica e mais contratações de servidores que laboram neste setor, bem como a continuidade no investimento para o aprimoramento tecnológico do sistema utilizado para o monitoramento eletrônico dos apenados.

Neste artigo, abordamos com maior ênfase, algumas melhorias tecnológicase humanas que alcançaram resultados positivos na repartição penitenciária em questão do estado do Rio Grande do Sul. A pesquisa foi pautada em: análise bibliográfica, entrevistas e estudos da repartição pública da $5^{\text {a }}$ Região Penitenciária do RS, que abrange a região Sul do estado do RS, contribuindo com a qualificação e a veracidade deste estudo, pretendendo assim colaborar em todas as esferas do sistema penitenciário brasileiro.

O plano de ação utilizado foi através de uma pesquisa-ação (TRIPP,2005), com a pesquisa da área de estudo do trabalho do Policial Penal do Monitoramento Eletrônico da $5^{\text {a }}$ Região do RS, e devido isso, ter a proximidade com o seu objeto de pesquisa. A coleta de dados foi realizada pelo meio de entrevistas com o Coordenador deste estabelecimento prisional, sendo observado a motivação dos profissionais e dos monitorados, contribuindo decisivamente para o desenvolvimentodeste projeto.

A meta e objetivo deste artigo, foi de contribuir através de uma pesquisa especifica com base em ações que estão gerando resultados positivos sobre o monitoramento eletrônico prisional desta localidade.

O intuito de cooperar com o sistema de monitoramento eletrônico brasileiro, neste trabalho foi latente, através do estudo realizado mostrando ideias que consistem em desenvolver um projeto ideal de monitoramento eletrônico.

O levantamento foi dividido em dois momentos: inicialmente na pesquisa- ação e posteriormente foi analisada a repartição com níveis de ideologias diferentes. Com vista disso e através da imersão dos ambientes pesquisados, devemos levarem consideração o projeto inicial, e o seu melhoramento com o passar do tempo, projetos que não deram certo 
ou não iniciados, já que o crescimento de umainstituição depende de diversos fatores.

\section{DESENVOLVIMENTO}

O trabalho este iniciado foi em uma instituição que adotou está medida de segurança que deu certo. A instituição escolhida foi a SUSEPE (Superintendência de Serviços Penitenciários do Rio Grande do Sul) / Divisão Monitoramento Eletrônico/ $5^{\circ}$ região Sul (Pelotas).

Os passos da pesquisa-ação consistiram em: planejamento que envolve o conhecimento e reconhecimento da situação, ação e reflexão. A metodologia da pesquisaação é considerada um sistema aberto, isso porque diferentes rumos podem ser tomados no decorrer do seu desenvolvimento em função das demandas encontradas. Inicia-se evidentemente com um planejamento. Porém, conforme afirma Thiollent (20II), há um ponto de partida, que é a fase exploratória, e um ponto de chegada, referindo-se à divulgação dos resultados, mas no intervalo haverá uma multiplicidade de caminhos em função das diferentes situações diagnosticadas ao longo do processo.

O Rio Grande do Sul é um dos estados pioneiros em monitoramento eletrônico no Brasil, sendo instaurado na organização em 2013, incialmente em sua capital a cidade de Porto Alegre, onde desde então foi tentado o aprimoramento gradual do sistema de tornozeleiras eletrônicas.

De acordo com Engel e Poliese (2013), o monitoramento eletrônico é uma maneira de gestão prisional que está sendo instaurada com a finalidade de diminuir a população carcerária, sendo assim a medida que o desenvolvimento vai acontecendo, mais o encarceramento dos apenados diminuem. Portanto a ideia principal dessa pesquisa é contribuir para que essa progressão seja concretizada.

Este artigo se trata de um trabalho de campo presencial e também documental, visto que a pesquisa aborda ações de condutas dentro do âmbito legal, com relatos de uma organização de cumprimento de pena alternativa. Devido à proximidade do pesquisador com o ambiente pesquisado a metodologia empregada foi a pesquisa-ação que segundo Thiollent (2011):

A pesquisa-ação é um tipo de pesquisa social com base empírica que é concebida e realizada em estreita associação com uma ação ou com a 
resolução de um problema coletivo e no qual os pesquisadores e os participantes representativos da situação ou do problema estão envolvidos de modo cooperativo ou participativo. (THIOLLENT, 20II, p.I4)

A terceira tecnologia é a que vai ser ressaltada neste estudo, já que essa situação se diferencia das demais circunstâncias de monitoramento que ocorrem, pois cada monitorado tem suas peculiaridades e por sua vez necessitam de cuidados diferenciados, além de tratar-se de um monitoramento diferenciado por ser uma implantação subcutânea.

De certo o monitoramento eletrônico é considerado por muitos juristas um novo instrumento para as políticas penais, desta maneira consideramos importante aintegração entre os poderes executivos, legislativo, judiciário e principalmente da sociedade para o desenvolvimento dessa ação.

No estado do Rio Grande do Sul têm três tecnologias essenciais para o andamento do processo: telefonia, GPS (Global System Positioning) e inovações tecnológicas geradoras de polêmicas (Japiassú \& Macedo, 2008; Manfroi, 2013), taiscomo:

[...] conflitos de ordem religiosa, médica e ética, já que poderia ser viabilizada através da implantação subcutânea de chips de rádio freqüência (RFID) atualmente existe um protótipo conhecido por Very Chip (Becker, 2008) - porém, devido à intervenção corporal que acarreta, entendese que viola o princípio da dignidade humana e o próprio corpo biológico, com o risco de malefícios, já que os efeitos, do ponto de vista científico, não são conclusivos ( $f a z$-se a ressalva de que já estaria sendo aplicada para monitoração de animais domésticos) (ENGEL; POLESE,2013,p.I).

É uma pesquisa qualitativa, conforme Bortoni-Ricardo (2008):

[...]não se procura observar a influência de uma variável em outra. O pesquisador está interessado em um processo que ocorre em determinado ambiente e quer saber como os atores sociais envolvidos nesse processo o percebem, ou seja: como interpretam. (BORTONI-RICARDO, 2008, p.34)

\section{APRESENTAÇÃO DO PROJETO}

O estudo desse artigo basicamente se desenvolve no Instituto penal de monitoramento da $5^{\circ}$ região, localizado na cidade de Pelotas (RS). Esse instituto compreende várias cidades da região Sul do Rio Grande do Sul como Rio grande, Santa Vitória do Palmar, Jaguarão, Canguçu e Pelotas.

O estabelecimento penal do estudo foi o penúltimo a ser inaugurado no estado do RS em meados do ano de 2018, embora sendo recente ela tem inovações, que vão ser estudadas nesse artigo, que outras instituições ainda não aderiram. Inicialmente o equipamento 
utilizado era de um determinado fabricante (Tornozeleira AGK),

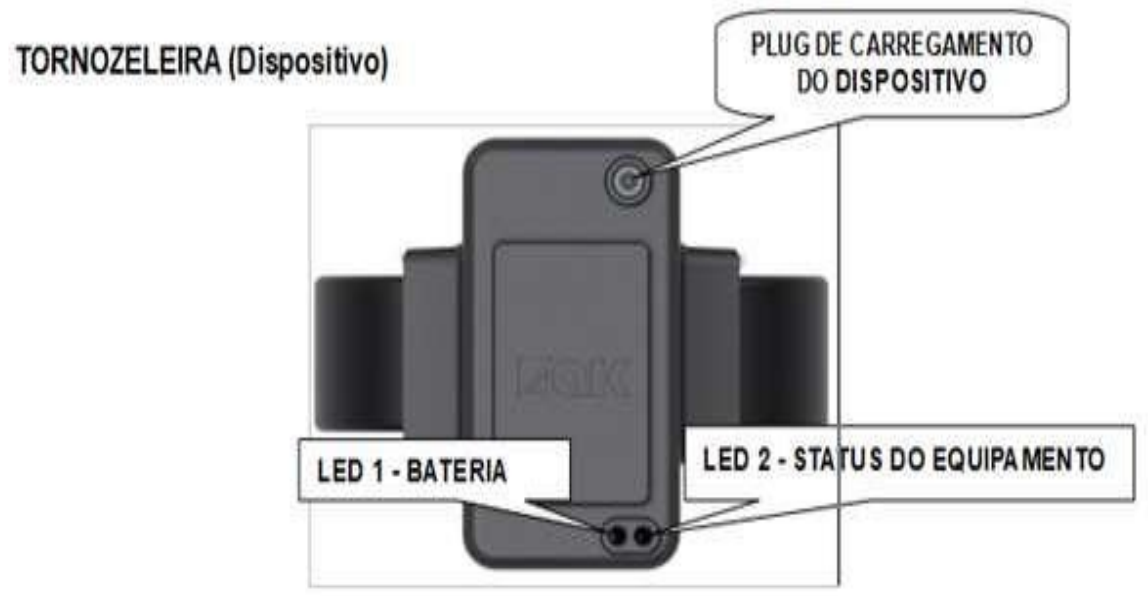

(Fonte: Susepe-Tornozeleira AGK - 2018)

Por haver necessidades que não estavam sendo cumpridas, o departamento penitenciário do RS decidiu realizar a contratação de um novo equipamento, da empresa Georastreamento, implementado em 2019, equipamento este mais moderno para alcançar todas as exigências necessárias para a devida custódia e controle dos apenados que usam tornozeleiras eletrônicas no estado do RS. "Essa é uma vitória da perseverança e do panejamento bem estruturado e,especialmente, do engajamento e da dedicação de nossos servidores", comemorouo secretário da Administração Penitenciária, Cesar Faccioli. Além de expressiva, a marca cumpre uma das metas estabelecidas pelo atual governo. O contrato das novas tornozeleiras, com tecnologia suíça, prevê a instalação de Io mil equipamentos, ao custo de $\mathrm{R} \$ 40$ milhões.

A nova tornozeleira, da empresa Geo Rastreamento, é produzida com um material mais rígido e suporta até $500 \mathrm{kgf}$ (quilograma força), eliminando, assim, qualquer dúvida quanto ao rompimento doloso por parte do apenado ou da apenada.A bateria tem duração de até 24 horas. 
Imagem (Antiga e nova tornozeleira)

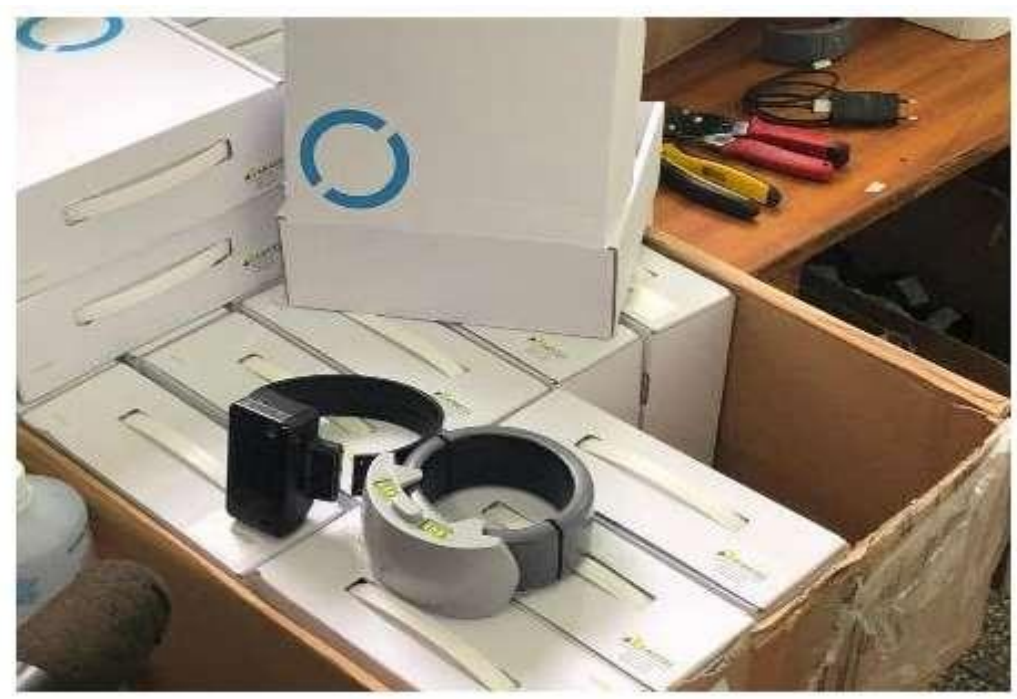

(Fonte: Susepe-Tornozeleira Geo Rastreamento 2019)

Imagens (Nova tornozeleira)
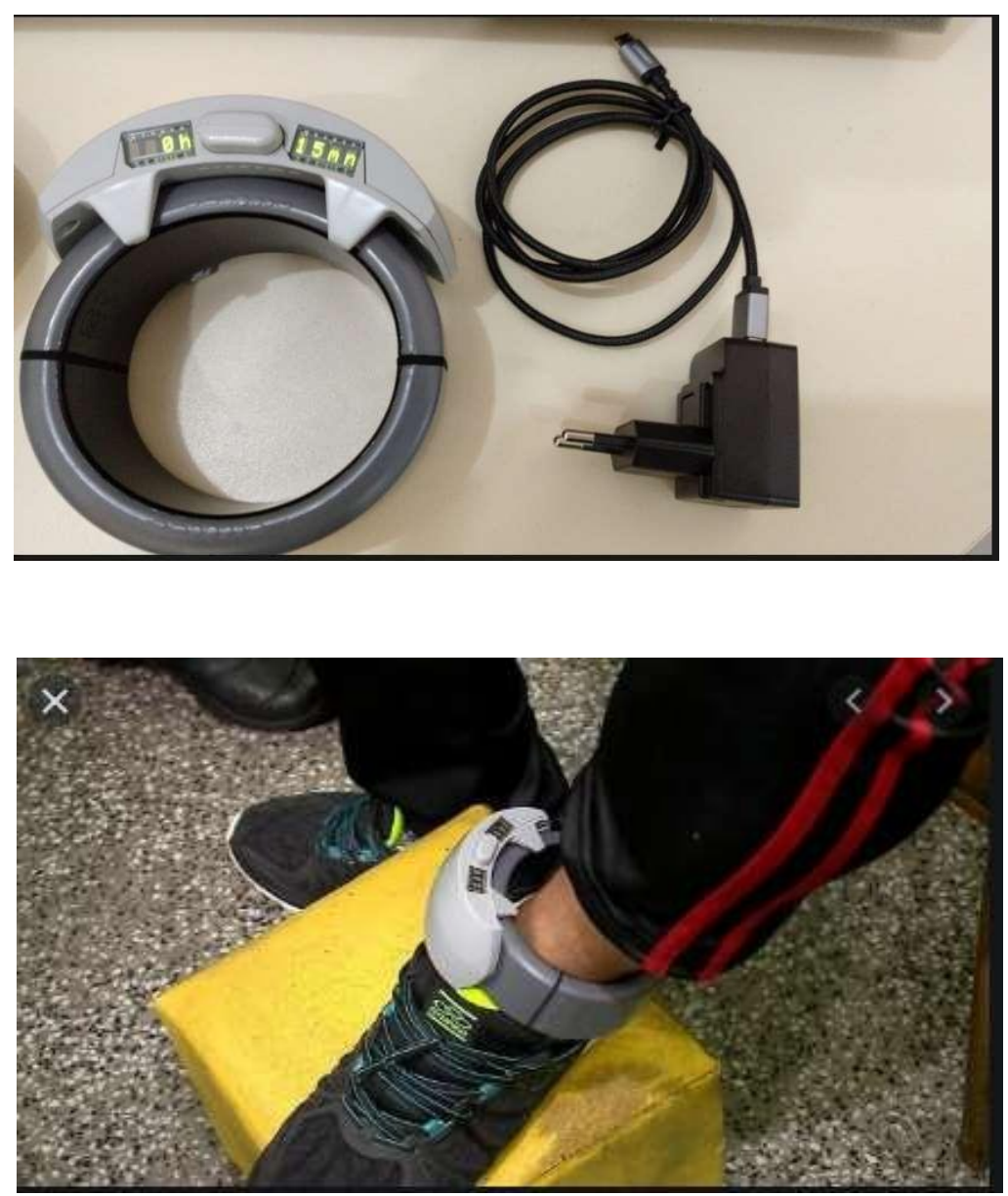

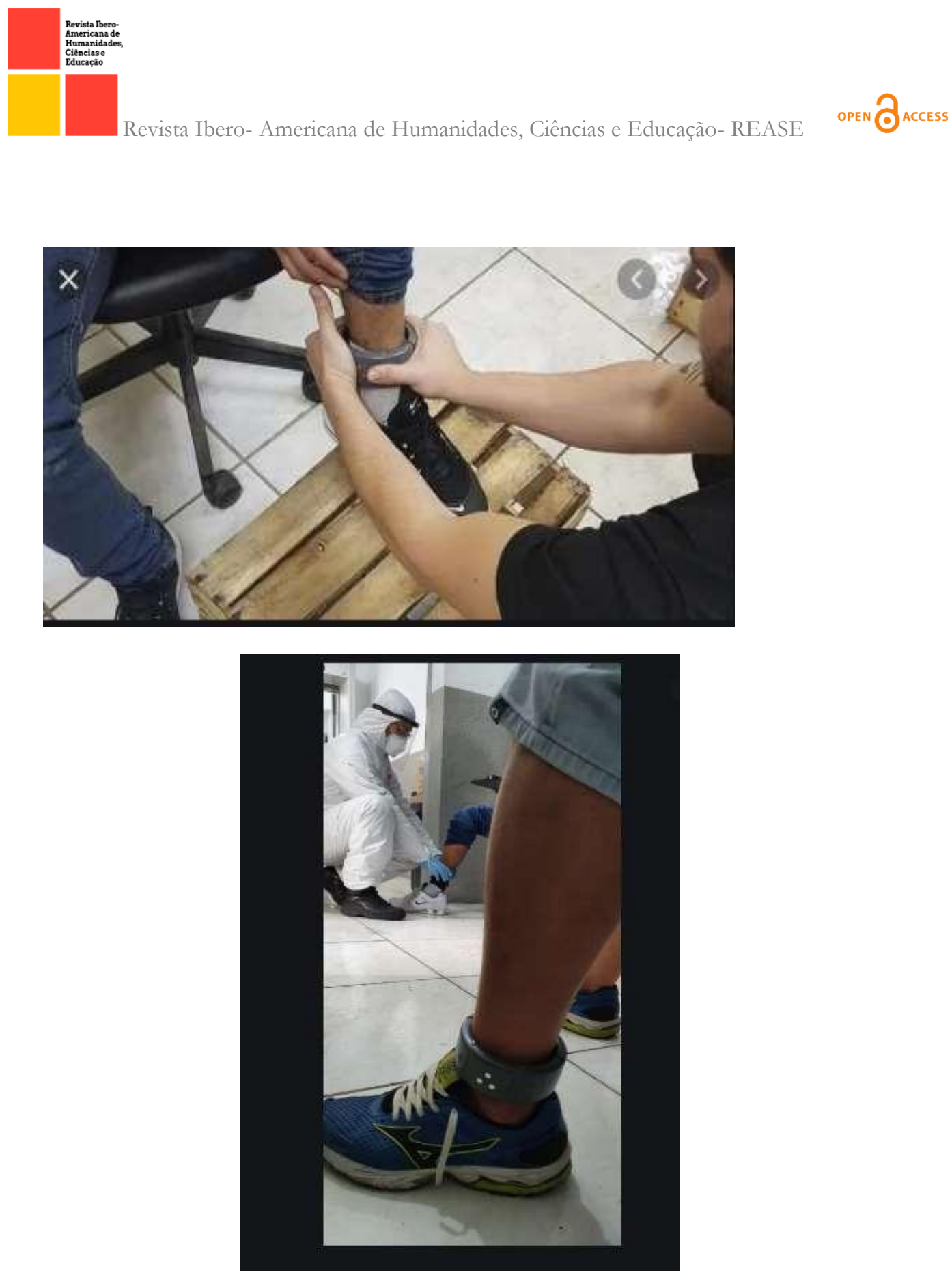

(Fonte: Susepe-Tornozeleiras Geo Rastreamento 2019)

O monitoramento eletrônico da região sul do Rio Grande do Sul, apresentou um diferencial das demais instituições, já que desde o começo considerou a visão humanística, não somente os dados técnicos. Em contramão a está visão reducionista, o dinamismo do cotidiano desse trabalho mostrou que a atividade necessita de uma estrutura psicossocial e material por parte dos interessados.

Com o decorrer do andamento das atividades do IPME5 RS, foi percebido que os apenados que tinham o direito para a instalação de tornozeleiras eletrônicas, violavam as 
regras do monitoramento eletrônico, acarretando uma grande evasão, sendo passados a condição de foragidos, e posteriormente ingressavam novamente para o sistema fechado, ou seja, dentro das cadeias. Muitas destas transgressões, foram rompimentos das tornozeleiras, com a perda do material, o estado arca comos prejuízos, já que de acordo com o sistema GEOPÓLIS, prevê que cada aparelho perdido ou danificado custa em média de R\$6oo,oo.

Com o passar do tempo as regras do departamento foram sendo aprimoradas, e por conseguinte foi preciso elaborar uma maneira para que osmonitorados fossem adequados a sistemática da organização para evitar que não fossem punidos a ponto de serem excluídos do monitoramento e por consequência disso, voltando para o regime fechado.

Diariamente são publicados os foragidos da tornozeleira, bem como informações pertinentes a sua captura e retorno ao sistema fechado. Dessa forma, através da localização da tornozeleira, são realizadas as comunicações para a prisão dos foragidos, proporcionando uma maior assertividade e segurança ao policial. As comunicações de fuga poderão apresentar o nome do monitorado, regime em que se encontra, violação cometida, data e hora da ocorrência, endereço,coordenadas de localizações e observações pertinentes.

Salienta-se também, que todas as informações que são geradas pelas tornozeleiras eletrônicas do IPME5-RS são de propriedade do judiciário local, e só é permitido seu compartilhamento com demais órgão do executivo mediante autorização judicial prévia. Sendo assim, para que este projeto seja devidamente efetivado foi necessário a elaboração de uma ordem de serviço da VEC Regional de Pelotas autorizando o compartilhamento dessas informações para os membros de outros órgãos de segurança para a posterior captura do apenado foragido dastornozelerias eletrônicas.

Dessa forma, para o monitorado ter mais ciência e responsabilidade para seadaptar ao sistema das tornozeleiras, é colhida no ato da instalação a assinaturacom a ciência dos apenados, que qualquer violação/danificação ou não devolução do equipamento de monitoramento este será responsabilizado por crime doloso de dano ao patrimônio público ou enquadrado em outro delito previsto em lei. Também são orientados que a tornozeleira deverá ser recarregada três vezes por dia. Nos casos em que houver descarga total do dispositivo, o monitorado será passado para a condição de foragido, entrar em contato com o IPME caso surja alguma necessidade de urgência, deverá manter seu celular em funcionamento e com som habilitado para escutar as ligações do IPME5-RS, atender as 
ligações e tratar com educação os agentes do monitoramento.

Todos esses novos métodos contribuíram de forma relevante no cumprimento das penas dos apenados no monitoramento eletrônico da $5^{\underline{a}}$ Região- RS, no sentido organizacional, houve uma redução considerável de evasão, contribuindo para o não retrocesso dos indivíduos que cumprem pena, além de diminuir os gastos do estado com tornozeleira perdida ou danificada.

\section{ILUSTRAÇÕES}

\section{1 - Regiões $5^{\circ}$ IPME}

Página Inicial $>$ Presídios - Delegacias Penitenciárias $>5^{\circ}$ DPR - Sul (sede em Pelotas)

$\leftarrow$ Voltar A RSS E Compartilhar Imprimir A A

5 aPR - Sul (sede em Pelotas)

Substância ilícita é encontrada c

- $5^{3}$ Delegacia Penitenciária Regional - Sede em Pelotas

- Penitenciária Estadual de Rio Grande

- Presidio Estadual de Camaquã

- Presidio Estadual de Canguçu

- Presidio Estadual de Jaguarāo

- Presidio Estadual de Santa Vitória do Palmar

- Presidio Regional de Pelotas

Fonte: SUSEPE (202I)

\section{2 - Efetivo Carcerário $5^{\circ}$ região RS}

\begin{tabular}{|c|c|c|c|c|c|c|}
\hline $\begin{array}{c}\text { 5a Região Penitenciária } \\
12 \text { Unidades Prisionais }\end{array}$ & 骂 荘 & 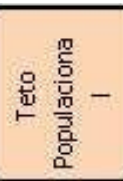 & 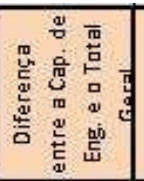 & 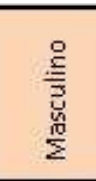 & 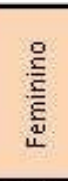 & $\begin{array}{l}\text { Total } \\
\text { Geral }\end{array}$ \\
\hline Instituto Penal de Monit. Eletrônico 5 e Região & $\emptyset$ & $\emptyset$ & $\emptyset$ & 602 & 39 & 641 \\
\hline PE de Camaquã & 150 & 150 & -224 & 374 & 0 & 374 \\
\hline Anexo do PE de Canguçu & 22 & 52 & 22 & 0 & 0 & $\mathbf{0}$ \\
\hline PE de Jaguarão & 38 & 84 & -46 & 84 & 0 & 84 \\
\hline Anexo do PE de Jaguarão & 14 & 38 & 14 & 0 & 0 & $\mathbf{0}$ \\
\hline PE de Sta. Vitória Palmar & 48 & 48 & 36 & 84 & 0 & 84 \\
\hline Penit. Est. de Rio Grande & 448 & 448 & -341 & 713 & 76 & 789 \\
\hline Total 5 a Regiào & 1326 & 1449 & -780 & 2.632 & 115 & 2747 \\
\hline
\end{tabular}

\section{(Fonte: Susepe 202I)}




\section{CONCLUSÃO}

Podemos observar que este artigo elucidou através dos envolvidos, que a gestão prisional do monitoramento eletrônico dos apenados da $5^{\text {a }}$ Região-RS (IPMEs), está sendo desenvolvida a medida que o sistema está sendo modernizado, além do aprimoramento das normas e regras realizadas aos apenados que cumprem a pena de reclusão nas tornozeleiras eletrônicas, tendo por objetivo real, a reinserção do apenado na sociedade e além disso proporcionar o retorno ao âmbito familiar.

Em um primeiro momento, podemos concluir que é de extrema relevância e vantagens o uso do monitoramento eletrônico tanto para o Estado quanto para os próprios monitorados, podemos citar por exemplo a diminuição da problemática dos presídios superlotados e o custo menor de manter um preso mensalmente no sistema de monitoramento eletrônico.

A proporção que o sistema vai se solidificando, deve-se verificar que a chance dada a um preso de ingressar no sistema das tornozeleiras eletrônicas será de grande relevância para a sua recuperação e inserção na sociedade, sendo de forma educativa e social a melhor maneira.

Mediante este artigo, concluímos que através do uso da tecnologia digital, ecom o maior implemento do sistema de monitoramento eletrônico nos apenados do sistema carcerário, será de fundamental importância para a economia dos estados brasileiros bem como no trabalho de retorno dos presos ao convívio social, pois ao ingressar um apenado no sistema de monitoramento eletrônico das tornozeleiras, o custo para a instituição com está aplicação é muito reduzido comparado com os custos de manter o apenado dentro de um presídio.

\section{REFERÊNCIAS}

BRASIL. Lei no 12.258 , de 15 de junho de 2010. Diário Oficial da União, i6 jun 2010. Altera o Decreto-Lei no 2.848, de 7 de dezembro de 1940 (Código Penal), e a Lei no 7.210, de II de julho de 1984 (Lei de Execução Penal), para prever a possibilidade de utilização de equipamento de vigilância indireta pelo condenado nos casos em que especifica.Disponível em:< http://www.planalto.gov.br/ - 2010/2010/lei/li2258.htm〉. Acesso em 23/12/2013.

ENGEL, Luciane; POLESE, Gustavo. Monitoração eletrônica: as nuances da nova tecnologia.ArtigoCrprs,2013.Disponívelem:<http://www.cprs.org.br/dowload/artigo_Prisi 
onal.pdf $>$. Acesso em: I8 de jan. de 2019 .

SUSEPE: Sistema GEÓPOLIS e Mapas. Disponível em: 〈http://www.intrasusepe.rs.gov.br/ehttp://www.intrasusepe.rs.gov.br/conteudo/6509/?Ano_2019〉. Acesso em: $\mathrm{mm}$

BECKER, S. W. O efeito das novas tecnologias no sistema de justiça criminal: críticas à experiência dos Estados Unidos: in Monitoramento Eletrônico: Uma Alternativa à Prisão? Experiências Internacionais e Perspectivas no Brasil. Brasília, Conselho Nacional de Política Criminal e Penitenciária, Brasil, zo Semestre de 2008.

BORTONI-RICARDO, Stella Maris, 1945. O professor pesquisador: introdução à pesquisa qualitativa / Stella Maris Bortoni-Ricardo. - São Paulo: Parábola Editorial, 2008.

JAPIASSÚ, C. E. A. \& MACEDO, C. M. O Brasil e o Monitoramento Eletrônico: in Monitoramento Eletrônico: Uma Alternativa à Prisão? Experiências Internacionais e Perspectivas no Brasil. Brasília, Conselho Nacional de Política Criminal e Penitenciária, Brasil, 2- Semestre de 2008.

THIOLLENT, Michel. Metodologia da pesquisa-ação. ı8. ed. São Paulo: Cortez, 20 II.

TRIPP, David. Pesquisa-ação: uma introdução metodológica. Educação e pesquisa,v. 3I, n. 3, p. 443-466, 2005. https://doi. org/10.1590/S1517-97022005000300009. 